\title{
Uncomplicated Pregnancies and Ultrasounds for Fetal Growth Restriction: A Pilot Randomized Clinical Trial
}

\author{
Ibrahim A. Hammad, MD ${ }^{1}$ Suneet P. Chauhan, MD ${ }^{2}$ Malgorzata Mlynarczyk, MD, PhD ${ }^{1}$
} Nader Rabie, MD ${ }^{3}$ Chris Goodie, MD ${ }^{4}$ Eugene Chang, MD ${ }^{4}$ Everett F. Magann, MD ${ }^{3}$

Alfred Z. Abuhamad, MD ${ }^{1}$

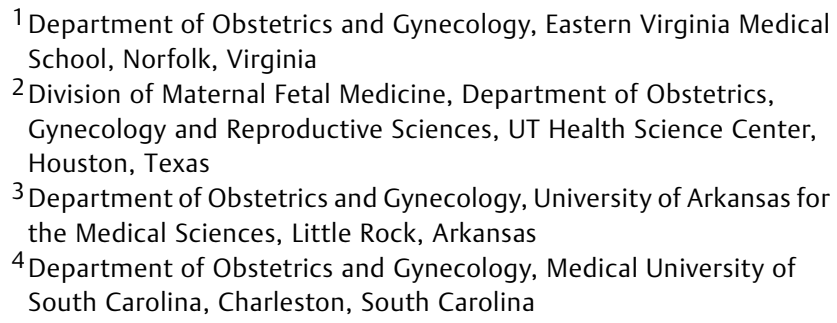

Address for correspondence Ibrahim A. Hammad, MD, Department of Obstetrics and Gynecology, Eastern Virginia Medical School, 825 Fairfax Avenue, Suite 544, Norfolk, VA 23517 (e-mail: drhammadia@gmail.com).

\author{
Abstract \\ Keywords \\ - small for gestational \\ age \\ - third trimester \\ ultrasound \\ - screening \\ - pilot study
}

Objective The purpose of this multicenter pilot study was to determine the feasibility of randomizing uncomplicated pregnancies (UPs) to have third trimester ultrasonographic exams (USE) versus routine prenatal care (RPNC) to improve the detection of small for gestational age (SGA; birth weight $<10 \%$ for GA).

Material and Methods At three referral centers, 50 UPs were randomized after gestational diabetes was ruled out. Women needed to screen, consenting, and loss to follow-up was ascertained, as was the detection rate of SGA in the two groups.

Results During the study period at the three centers, there were 7,680 births, of which $64 \%$ were uncomplicated. Of the 234 women approached for randomization, 36\% declined. We recruited 149 women and had follow-up delivery data on $97 \%$. The antenatal detection rate of SGA in the intervention group was $67 \%$ (95\% confidence intervals $31-91 \%)$ and $9 \%(0.5-43 \%)$ in control.

Conclusion The pilot study provides feasibility data for a multicenter randomized clinical trial to determine if third trimester USE, compared with RPNC, improves the detection of SGA and composite neonatal morbidity.

Small for gestational age (SGA), defined as actual birth weight below $10 \%$ for gestational age (GA), is linked with intraventricular hemorrhage, neonatal seizures, sepsis, necrotizing enterocolitis, prolonged hospitalization, and increased hospital charges. SGA, compared with appropriate for gestational age (AGA; birth weight between 10 and $90 \%$ for GA), is at increased risk of stillbirths and neonatal and infant mortality. ${ }^{1-8}$

received

July 28, 2015

accepted after revision

October 1, 2015

published online

November 16, 2015
According to six national guidelines, the mortality with SGA is reduced if fetal growth restriction (FGR)-sonographically estimated fetal weight (SEFW) $<10 \%$ for GA-is diagnosed, antenatal surveillance initiated, and delivery managed according to guidelines. ${ }^{1,9-13}$ American College of Obstetricians and Gynecologist (ACOG) currently recommends that screening for suboptimal growth involves assessing risk factors for SGA and,
Copyright $\odot 2016$ by Thieme Medical Publishers, Inc., 333 Seventh Avenue, New York, NY 10001, USA. Tel: +1(212) 584-4662.
License terms

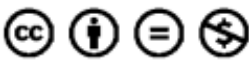

10.1055/s-0035-1567857. ISSN 2157-6998. 
starting at 24 weeks, measuring fundal height at prenatal visits. Ultrasonographic screening for FGR should be reserved for pregnancies at risk for SGA, inability to accurately measure fundal height due to obesity, or discrepancy between GA and fundal height. ${ }^{1}$

Utilization of risk-based screening paradigm in current clinical practice indicates that $69 \%$ of SGA were not identified prenatally ${ }^{14-20}$ and hence do not benefit from the antepartum surveillance. Alternatively, clinicians could universally screen for SGA with third trimester sonographic examinations ${ }^{21}$ but this may not be cost-effective, and it may lead to unnecessary interventions and iatrogenic prematurity. ${ }^{20,22}$ Thus, due to the equipoise between poor detection of SGA with current screening recommendations and the practice of routine ultrasonography in the third trimester, a randomized clinical trial (RCT) is warranted. ${ }^{21,22}$ McKenna et $\mathrm{al}^{21}$ calculated that over 30,000 women need to be randomized to demonstrate a $30 \%$ reduction in morbidity related to growth restriction. Before such a formidable RCT is undertaken, we sought to do a multicenter pilot RCT to assess the feasibility of randomizing uncomplicated women to ultrasonographic examinations (USEs) in the third trimester (intervention) versus routine prenatal care (RPNC), involving serial symphyseal fundal height (SFH) measurements ${ }^{1}$ and USE if there is a lag between GA and SFG or if there are obstetric complications (control).

The purpose of this pilot RCT was to determine the feasibility and logistical problems with randomizing women without any complications to USE in the third trimester versus RPNC.

\section{Material and Methods}

The study was conducted at three academic centers: Medical University of South Carolina (MUSC), University of Arkansas Medical Center (UAMC), and Eastern Virginia Medical School (EVMS). For this pilot RCT, we recruited a convenience sample of 50 women from each site, for a total of 150 women with uncomplicated pregnancies and confirmed gestational dates. Following a normal glucose tolerance screen at 26 to 29 weeks, participants were randomized into either a study intervention group in which women underwent two additional ultrasound examinations at 30 to 32 and 36 to 37 weeks or a control group which had RPNC, as determined by clinicians at the teaching hospital. Patients were randomized using the block randomization method from the Randomization computer program. The duration of this study was June 1,2012 , to July 10,2014 . The institutional review board approved the study at each center (Pro00017317, 127726, and 12-04-EX-0088 for MUSC, UAMC, and EVMS, respectively).

\section{Selection of Participants}

At the participating sites, clinicians were informed of this study. After being screened for gestational diabetes, the research staff described the study; if the patient indicated a willingness to participate, she was informed in detail about the study, including inclusion and exclusion criteria. She was provided with the study protocol and asked to sign the informed consent. Randomization was done when the gestational diabetes screening test was negative.

The inclusion criteria were nonanomalous singleton, fetal anatomy ultrasound by 22 weeks, and expected third trimester care and delivery at one of the participating hospitals. The exclusion criteria were any of the following: (1) autoimmune disorders (antiphospholipid antibody, lupus, rheumatoid arthritis, scleroderma); (2) cerclage in the index pregnancy; (3) diabetes mellitus-gestational or pregestational; (4) enrollment in another RCT; (5) hematologic disorders (coagulation defects, sickle cell disease, thrombocytopenia, thrombophilia); (7) hypertension (chronic or pregnancy induced) before randomization; (8) HIV (human immunodeficiency virus); (9) institutionalized individuals (prisoners); (9) obesity, defined as body mass index above $40 \mathrm{~kg} / \mathrm{m}^{2}$ at first prenatal visit; (10) prior obstetric history of intrauterine growth restriction, preterm birth before 34 weeks, severe preeclampsia, eclampsia, HELLP syndrome, or stillbirth after 24 weeks or neonatal death; (11) preterm labor or ruptured membranes before randomization; (12) psychiatric disorder (bipolar, depression) on medication; (13) placenta previa/ third trimester bleeding; (14) renal insufficiency (serum creatinine $>1.5 \mathrm{mg} / \mathrm{dL}$ ); (15) restrictive lung disease; (16) fetal red blood cell isoimmunization; (17) seizure disorder on medication; or (18) thyroid disease on medication.

\section{Study Procedures}

Pregnancy dating was confirmed ${ }^{23}$ based on the guideline recommended by ACOG, American Institute of Ultrasound in Medicine, and the Society of Maternal-Fetal Medicine. Since the accuracy of SEFW is optimum when done by a registered diagnostic medical sonographer (RDMS), the USE was done by RDMS. $^{24}$ In the intervention group, USE was done at 30 to 32 weeks and 36 to 37 weeks. Patients in either group may have additional ultrasounds if there were obstetric indications (clinical suspicion for abnormalities of fetal growth or amniotic fluid, third trimester bleeding, preeclampsia, preterm labor, or premature rupture of membranes) or if the clinician recommends it. ${ }^{25}$

Fetal growth was assessed by measuring the biparietal diameter (BPD) at the level of thalami and insula, the measurement taken from outer edge of the proximal skull to the inner edge of the distal skull. The head circumference (HC) was measured at the same level as the BPD, around the outer perimeter of the calvaria. The abdominal circumference (AC) measurement was obtained at the skin line on a true transverse view at the level of the junction of the umbilical vein, portal sinus, and the fetal stomach. Femur length (FL) was measured with the beam of insonation being perpendicular to the shaft, excluding the distal femoral epiphysis. ${ }^{25}$ Estimated fetal weight (EFW) was derived using the regression equation proposed by Hadlock et $\mathrm{al}^{26}: \log _{10}(\mathrm{EFW})=1.5662-0.0108(\mathrm{HC})+0.0034$ $(\mathrm{HC})^{2}+0.0468(\mathrm{AC})+0.171(\mathrm{FL})-0.003685(\mathrm{AC})(\mathrm{FL})$, with EFW being estimated fetal weight, $\mathrm{HC}$ head circumference, AC abdominal circumference, and FL femur length.

FGR was defined as $A C<10 \%$ for GA or EFW below $10 \%$ for $\mathrm{GA}^{10}$; large for gestational age (LGA) was $\mathrm{AC}>90 \%$ for GA or EFW $>90 \%$ for GA. Amniotic fluid was estimated using single 
sonographic deepest pocket (SDP) or amniotic fluid index (AFI). ${ }^{25}$ Oligohydramnios, or decreased amniotic volume, was an SDP less than $2 \mathrm{~cm}$ or AFI $<5.0 \mathrm{~cm}$; hydramnios, or excessive amniotic fluid, was SDP of $8 \mathrm{~cm}$ or AFI of $24.0 \mathrm{~cm}$ or more. ${ }^{27}$

The SFH, measured at each prenatal visit, was measured by identifying the variable point, the fundus, and then measuring to the fixed point, the symphysis pubis. The examiner used a measuring tape with the centimeter marks turned away, thus not visible. ${ }^{10}$ Once the measurement was taken, the measuring tape was turned and the fundal height noted in centimeter. Besides the intervention of two sonographic examinations in the third trimester, the management of the pregnancy was at the discretion of the clinicians at each center. After delivery and discharge of the newborn, the authors at each center completed the data sheet on the maternal and neonatal outcomes. Obstetric complications after randomization consisted of the following: hypertension, preterm labor, premature rupture of membranes, and decreased fetal movement. The composite neonatal morbidity (CNM) consisted of one of the following: respiratory distress syndrome, transient tachypnea of the newborn, hyperbilirubinemia, seizures, hypoglycemia, proven sepsis, intraventricular hemorrhage III/IV, or necrotizing enterocolitis.

\section{Statistical Analyses}

CONSORT guideline with intent-to-treat principle was utilized. $^{22 ;}$ Continuous variables were compared by means of independent sample $t$-tests or the Wilcoxon rank sum test, and categorical variables by the chi-square or Fisher exact test, as appropriate. The data were analyzed using SAS 9.4 edition EVMS. Predictive accuracies for identifying SGA and LGA newborns were calculated.

\section{Results}

During the study period at the three hospitals, there were 7,680 deliveries, of which $64 \%$ were $(n=4,943)$ uncomplicated. Of the 234 women which met the inclusion criteria and were approached for the study, 36\% ( $n=85$ ) refused participation and $64 \%(n=149)$ were consented and randomized. The antepartum variables were available for all 149 women. Four women from one center (3\%) delivered at an outside hospital and thus intrapartum and neonatal data are unavailable for analysis (-Fig. $\mathbf{1}$ ).

- Table 1 provides the maternal demographics of the 149 randomized women. The majority of the women in both groups were nulliparous and 3\% of the women in both groups had prior preterm births between 34 and 36 weeks. The GA at randomization was similar for both the groups. In the control group, $21 \%$ had sonographic examination after the randomization. The likelihood of having obstetric complications was similar in the two groups (27 vs. 25\%; - Table 1).

The frequency of sonographic examinations and abnormal findings are provided in - Table $\mathbf{2}$. The reasons women in the intervention group did not have sonographic examinations-

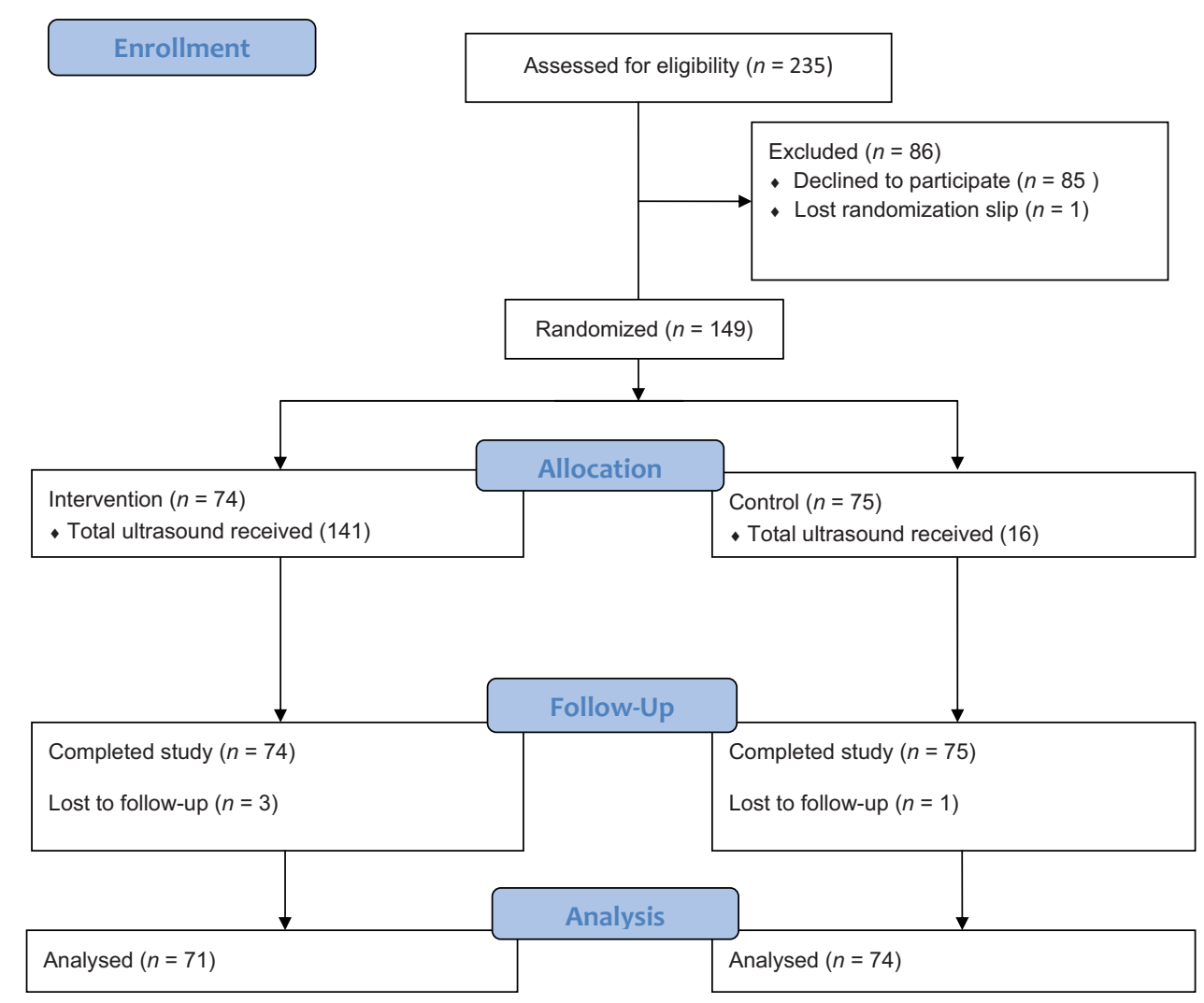

Fig. 1 Flow diagram. 
Table 1 Maternal and antenatal characteristics

\begin{tabular}{|c|c|c|c|c|}
\hline & USE $(N=74)$ & Control $(N=75)$ & $p$ & RR $(95 \% \mathrm{Cl})$ \\
\hline Age & $25.6 \pm 5.4$ & $26.5 \pm 5.3$ & & \\
\hline \multicolumn{5}{|l|}{ Ethnicity } \\
\hline Afro-American & $40(54 \%)$ & $24(32 \%)$ & \multirow[t]{4}{*}{0.009} & \\
\hline Caucasian & $31(42 \%)$ & $48(64 \%)$ & & \\
\hline Hispanic & $0(0 \%)$ & $1(1 \%)$ & & \\
\hline Other & $3(4 \%)$ & $2(3 \%)$ & & \\
\hline Nulliparous & $39(53 \%)$ & $38(51 \%)$ & 0.86 & \\
\hline Prior preterm birth at $34-36 \mathrm{wk}$ & $2(3 \%)$ & $2(3 \%)$ & 1.00 & \\
\hline BMl at first visit $\left(\mathrm{kg} / \mathrm{m}^{2}\right)$ & $25.0 \pm 5.3$ & $25.6 \pm 5.8$ & 0.78 & \\
\hline BMI at delivery $\left(\mathrm{kg} / \mathrm{m}^{2}\right)$ & $28.9 \pm 5.1$ & $29.1 \pm 3.9$ & 0.89 & \\
\hline First ultrasound examination at (wk) & $14.4 \pm 3.2$ & $15.0 \pm 3.2$ & 0.88 & \\
\hline Gestational age at randomization & $28.3 \pm 2.0$ & $28 \pm 2.1$ & 0.84 & \\
\hline Complication after randomization & $20(27 \%)$ & $19(25 \%)$ & \multirow[t]{6}{*}{0.85} & \\
\hline Hypertension & $6(8 \%)$ & $10(13 \%)$ & & \\
\hline Preterm labor & $4(5 \%)$ & $1(1 \%)$ & & \\
\hline PPROM & 0 & 0 & & \\
\hline Decreased fetal movement & $4(5 \%)$ & $5(7 \%)$ & & \\
\hline Other & $6(8 \%)$ & $3(4 \%)$ & & \\
\hline USE for EFW after randomization & 141 & 16 & - & - \\
\hline 1st (32-34 wk) & $72(97 \%)$ & $6(8 \%)$ & & \\
\hline 2nd (36-37 wk) & 69 (93\%) & $10(13 \%)$ & & \\
\hline US/EFW for other reasons & $1(1 \%)$ & $16(21 \%)$ & 0.001 & $0.11(0.006-0.56)$ \\
\hline
\end{tabular}

Abbreviations: BMI, body mass index; EFW, estimated fetal weight; PPROM, preterm premature rupture of membranes; USE, ultrasound examination. Note: Data presented as mean \pm standard deviation or $N(\%)$.

Table 2 Sonographic examinations

\begin{tabular}{|c|c|c|c|c|}
\hline & USE $(N=74)$ & Control $(N=75)$ & $p$ & RR (95\% Cl) \\
\hline \multicolumn{5}{|c|}{ Based on USE, suspected FGR } \\
\hline $32-34$ wk & $6(8 \%)$ & $3(4 \%)$ & 0.32 & $1.37(0.62-1.93)$ \\
\hline $36-37$ wk & $7(9 \%)$ & $2(3 \%)$ & 0.09 & $1.92(0.81-2.05)$ \\
\hline \multicolumn{5}{|c|}{ Based on USE, suspected LGA } \\
\hline $32-34$ wk & $4(5 \%)$ & 0 & 0.06 & $1.83(1.27,2.65)$ \\
\hline $36-37$ wk & $12(16 \%)$ & 0 & $<0.001$ & $2.12(1.71,2.63)$ \\
\hline \multicolumn{5}{|l|}{ Amniotic fluid } \\
\hline Oligohydramnios & $2(3 \%)$ & $1(1 \%)$ & 0.62 & $1.35(0.25-2.02)$ \\
\hline Polyhydramnios & $5(7 \%)$ & $2(3 \%)$ & 0.27 & $1.47(0.61-2.00)$ \\
\hline Antepartum surveillance & $24(32 \%)$ & $1317 \%)$ & 0.03 & $2.28-(0.99-5.32)$ \\
\hline Biophysical profile & $2(3 \%)$ & $1(1 \%)$ & 0.62 & $1.35(0.25-2.02)$ \\
\hline NST/AF assessment & $22(30 \%)$ & $12(16 \%)$ & 0.05 & $1.43(0.96-1.91)$ \\
\hline
\end{tabular}

Abbreviations: AC, abdominal circumference; AF, amniotic fluid; EFW, estimated fetal weight; FGR, fetal growth restriction; GA, gestational age; LGA, large for gestational age; NST, nonstress test; USE, ultrasonographic examination.

Note: Data presented as mean \pm standard deviation or $N(\%)$. 
Table 3 Intrapartum characteristics

\begin{tabular}{|c|c|c|c|c|}
\hline & USE $(N=71)^{a}$ & Control $(N=74)^{a}$ & $p$ & RR $(95 \% \mathrm{Cl})$ \\
\hline Gestational age at delivery & $38.8 \pm 1.3$ & $39.2 \pm 1.2$ & 0.47 & \\
\hline Delivery at $<37 \mathrm{wk}$ & $3(4 \%)$ & $2(3 \%)$ & 0.67 & $1.23(0.34-1.94)$ \\
\hline \multicolumn{5}{|c|}{ Induced only for ultrasonographic abnormalities } \\
\hline$<37$ wk & 0 & 0 & - & - \\
\hline $38-39 w k$ & 0 & 0 & - & - \\
\hline \multicolumn{5}{|l|}{ Labor } \\
\hline Spontaneous & $38(53 \%)$ & $39(52 \%)$ & 1.00 & $1.01(0.71-1.46)$ \\
\hline Induction & $29(40 \%)$ & $30(40 \%)$ & 1.00 & $1.01(0.69-1.43)$ \\
\hline \multicolumn{5}{|l|}{ Route of delivery } \\
\hline Spontaneous vaginal delivery & $53(74 \%)$ & $54(73 \%)$ & 1.00 & $1.01(0.69-1.57)$ \\
\hline Operative vaginal delivery & $2(3 \%)$ & $5(7 \%)$ & 0.44 & $0.57(0.10-1.44)$ \\
\hline Cesarean delivery & $16(23 \%)$ & $15(20 \%)$ & 0.84 & $1.07(0.66-1.55)$ \\
\hline \multicolumn{5}{|l|}{ Indications for cesarean delivery } \\
\hline Nonreassuring FHR & $4(5 \%)$ & $6(8 \%)$ & 0.74 & $0.80(0.27-1.52)$ \\
\hline Cephalopelvic disproportion & $6(8 \%)$ & $5(7 \%)$ & 0.76 & $1.12(0.49-1.76)$ \\
\hline Other & $6(8 \%)$ & $4(5 \%)$ & 0.52 & $1.27(0.55-1.86)$ \\
\hline
\end{tabular}

Abbreviations: FHR, fetal heart rate; USE, ultrasonographic examination.

Note: Data presented as mean \pm standard deviation or $N(\%)$.

${ }^{a}$ Three women in intervention and one in control group were lost to follow-up because they delivered at a different hospital with no access to records.

two at 32 to 34 weeks and five at 36 to 37 weeks-were that they did not show up for the appointment. Women in the control group (21\%) had ultrasound exams because of the obstetric complications they developed after randomization. LGA was not suspected in the control group. The likelihood of having antepartum surveillance was similar.

- Table 3 describes the intrapartum characteristics of the two groups. No women in the pilot study underwent induction before 39 weeks for abnormalities noted on sonographic examinations. The rate of preterm birth and route of delivery were similar in the two groups. The neonatal outcomes are presented in -Table 4. The CNM occurred in $8 \%$ of the intervention group and $3 \%$ of the control group, a nonsignificant difference.

The predictive accuracy of the last ultrasound exam to identify SGA or LGA is provided in - Table 5 . The sensitivity of detecting SGA in the intervention group (67\%; 95\% confidence intervals $31-91 \%$ ) was higher than in the control group (9\%; 95\% confidence intervals $0.5-43 \%$ ). Over half of the LGA were detected in the intervention group, and it was not calculable for the control group.

\section{Discussion}

The pilot RCT provides data to undertake a multicenter study to ascertain if screening uncomplicated pregnancies with third trimester USE improves outcomes. ${ }^{21,22}$ At three geographically dispersed referral centers, about two-thirds of the women were uncomplicated and eligible for an RCT. When the eligible women were approached for randomization, the majority (64\%) consented for participation. The maternal and neonatal data until discharge were available in over $95 \%$ of women recruited. Previously, McKenna et $\mathrm{al}^{21}$ noted that $\sim 30,000$ women need to be randomized to show a reduction in morbidity by $30 \%$. With data on recruitment capabilities at three centers, a network with $\sim 140,000$ births per year could complete such a large randomized trial in 4 years.

There are several reasons such a large RCT is warranted. In 2012, out of 3.9 million births in the United States, there were $\sim 395,284$ SGA newborns. These pregnancies do not benefit from bed rest, nutritional counseling, or supplementation. ${ }^{1}$ They do benefit if the abnormal growth is identified, and if antepartum surveillance and evidence-based recommendations are implemented. ${ }^{1,9-13}$ Since about one-third of SGA are identified prenatally, ${ }^{14-20}$ we estimate that nationally over 270,000 SGA may not benefit from antepartum surveillance. Moreover, there is evidence that the CNM is significantly higher among undetected SGA than those that were detected. ${ }^{15,18}$

Some of the concerns with an RCT of this magnitude were that it was unknown how many women in control arm would have USE and if additional ultrasound examinations will lead to diagnosis of abnormalities of amniotic fluid and unnecessary late preterm or early term deliveries. ${ }^{22}$ Based on our pilot $\mathrm{RCT}$, we estimate that approximately one in five women assigned to the control group will have USE after randomization. It is reassuring that no women in either group underwent induction before 39 weeks for abnormalities noted on sonographic examinations alone. Additionally, the rate of induction was similar in both groups.

The detection of SGA was appreciably higher among those that have USE (67\%) versus control (9\%). Prior retrospective 
Table 4 Neonatal characteristics

\begin{tabular}{|c|c|c|c|c|}
\hline & USE $(N=71)$ & Control $(N=74)$ & $p$ & $\operatorname{RR}(95 \% \mathrm{Cl})$ \\
\hline Female & $35(47 \%)$ & $40(53 \%)$ & 0.62 & $0.91(0.63-1.31)$ \\
\hline Birth weight & $3,225+419$ & $3,240+465$ & 0.82 & - \\
\hline SGA (Alexander: BW $<10 \%$ ) & $9(12 \%)$ & $11(15 \%)$ & 0.81 & $0.91(0.46-1.45)$ \\
\hline SGA detected antepartum ${ }^{a}$ & $6(67 \%)$ & $1(9 \%)$ & 0.03 & $1.87(0.97-2.15)$ \\
\hline LGA (Alexander; BW > 90\%) & $5(7 \%)$ & $3(4 \%)$ & 0.48 & $1.29(0.52-1.92)$ \\
\hline LGA detected antepartum ${ }^{\mathrm{b}}$ & $4(80 \%)$ & $0(0 \%)$ & 0.06 & $2.07(1.69-2.55)$ \\
\hline Macrosomia $(\geq 4,000 \mathrm{~g})$ & $2(3 \%)$ & $4(5 \%)$ & 0.68 & $0.67(0.12-1.57)$ \\
\hline Macrosomia detected antepartum & 0 & 0 & - & - \\
\hline AS $<4$ at $1 \mathrm{~min}$ & $2(3 \%)$ & $3(4 \%)$ & 1.00 & $0.81(0.14-1.73)$ \\
\hline AS $<4$ at 5 min & $2(3 \%)$ & 0 & 0.41 & $1.66(0.85-3.15)$ \\
\hline \multicolumn{5}{|l|}{ UApH } \\
\hline$<7.10$ & 0 & $4(5 \%)$ & 0.50 & $0.22(0.01-3.02)$ \\
\hline$<7.00$ & 0 & $2(3 \%)$ & 0.62 & $0.03-4.83$ \\
\hline NICU admission & $2(3 \%)$ & $2(3 \%)$ & 1.00 & $1.02(0.18-1.89)$ \\
\hline Composite neonatal morbidityc & $6(8 \%)$ & $2(3 \%)$ & 0.16 & $1.58(0.73-2.06)$ \\
\hline
\end{tabular}

Abbreviations: USE, ultrasonographic examination; RR, relative risk; Cl, confidence intervals; SGA, small for gestational age; LGA, large for gestational age; NICU, neonatal intensive care unit.

${ }^{\mathrm{a}}$ Fetus diagnosed as FGR (abdominal circumference or estimated fetal weight $<10 \%$ ).

${ }^{b}$ Fetus with abdominal circumference or estimated fetal weight $>90 \%$ for gestational age.

'Composite neonatal morbidity consisted of any of the following: respiratory distress syndrome, transient tachypnea of the newborn, hyperbilirubinemia, seizures, hypoglycemia, proven sepsis, intraventricular hemorrhage III/IV, necrotizing enterocolitis.

Table 5 Predictive accuracy of the last ultrasound exam for detecting abnormal growth

\begin{tabular}{|c|c|c|}
\hline & USE & Control \\
\hline \multicolumn{3}{|l|}{ Small for gestational age ${ }^{a}$} \\
\hline Sensitivity & $67 \%(31-91 \%)$ & $9 \%(0.5-43 \%)$ \\
\hline Specificity & $98 \%(90-99 \%)$ & $98 \%(90-100 \%)$ \\
\hline Positive predictive value & $85 \%(42-99 \%)$ & $50 \%(2-98 \%)$ \\
\hline Negative predictive value & $95 \%(86-99 \%)$ & $86 \%(76-93 \%)$ \\
\hline Positive likelihood ratio & $41.3(5.6-304.8)$ & $5.7(0.38-84.9)$ \\
\hline Negative likelihood ratio & $0.33(0.13-0.85)$ & $0.92(0.76-1.11)$ \\
\hline \multicolumn{3}{|l|}{ Large for gestational age ${ }^{b}$} \\
\hline Sensitivity & $80 \%(30-99 \%)$ & NC \\
\hline Specificity & $79 \%(66-87 \%)$ & $95 \%(86-98 \%)$ \\
\hline Positive predictive value & $22 \%(7-48 \%)$ & $5 \%(1-13 \%)$ \\
\hline Negative predictive value & $77 \%$ (52-93\%) & $94 \%(86-98 \%)$ \\
\hline Positive likelihood ratio & $3.7(1.9-7.14)$ & NC \\
\hline Negative likelihood ratio & $0.2(0.04-1.47)$ & NC \\
\hline
\end{tabular}

Abbreviations: NC, not calculable because of 0 in one of the cells; USE, ultrasonographic examination.

Note: Data presented as \% (95\% confidence intervals) or $N$.

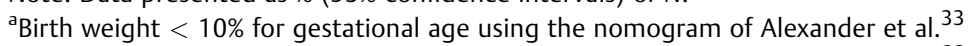

${ }^{b}$ Birth weight $>90 \%$ for gestational age using the nomogram of Alexander et al. ${ }^{33}$ 
studies $^{28,29}$ and randomized trials ${ }^{30}$ have also reported that with sonographic examinations done in the third trimester, 64 to $70 \%$ of SGA are accurately identified as being growth restricted. The detection of SGA in the control group was consistent with earlier publication ${ }^{17}$ that noted only $10 \%$ of SGA were detected in a tertiary center with the current management schema of serial SFH measurements and indicated USE.

Limitations of the pilot RCT should be acknowledged. The sample of 50 women from each center was one of convenience and of feasibility. Thus, the small sample size does not answer the clinically relevant question of: does the additional sonographic examination improve the neonatal outcomes? The three centers involved with the RCT are not part of the network and the findings may not be applicable to the current network in the United States. However, we think that the recruitment and follow-up of these women and newborns would be better in an established network than the three centers that participated. The results of our pilot study should not be used to calculate the sample for the RCT with the primary aim of determining the improvement with universal versus indicated third trimester ultrasound exams. The reason is that for the network trial the CNM should include uncommon sequela like hypoxic ischemic injury, proven seizure, necrotizing enterocolitis grade II or III, stillbirth, or neonatal death. These morbidities were so uncommon in our pilot study that our results are not applicable to the major trial. A priori we did not plan to follow the SGA and AGA newborns to confirm the metabolic and cardiovascular adaptive changes that putatively occur with growth restriction process. $^{31,32}$

The strengths of the pilot study should be acknowledged. Though McKenna et $\mathrm{al}^{21}$ did an RCT on the topic, it only involved one center while ours was a multicenter, which will be required to ascertain improvement in neonatal morbidity. Our findings can be used to calculate the sample size for women needed to screened, the likelihood of crossover, the detection of SGA, and the follow-up rate. The fact that the majority of the women in the tertiary centers are uncomplicated, and when informed about the study they consent, is reassuring.

In summary, our pilot study indicates that it is feasible to do a multicenter RCT study with the primary objective of answering the following question: do additional sonographic examinations in the third trimester compared with routine care improve the CNM in uncomplicated pregnancies? A multicenter RCT is warranted because of the equipoise between improved detection linked with lower morbidity and unnecessary interventions.

\section{References}

1 American College of Obstetricians and Gynecologist. Fetal Growth Restriction. ACOG practice bulletin No. 134. Washington, DC: American College of Obstetricians and Gynecologist; 2013

2 Garite TJ, Clark R, Thorp JA. Intrauterine growth restriction increases morbidity and mortality among premature neonates. Am J Obstet Gynecol 2004;191(2):481-487
3 McIntire DD, Bloom SL, Casey BM, Leveno KJ. Birth weight in relation to morbidity and mortality among newborn infants. N Engl J Med 1999;340(16):1234-1238

4 Gilbert WM, Danielsen B. Pregnancy outcomes associated with intrauterine growth restriction. Am J Obstet Gynecol 2003;188(6): 1596-1599, discussion 1599-1601

5 Bukowski R, Hansen NI, Willinger M, et al; Eunice Kennedy Shriver National Institute of Child Health and Human Development Stillbirth Collaborative Research Network. Fetal growth and risk of stillbirth: a population-based case-control study. PLoS Med 2014;11(4):e1001633

6 Trudell AS, Cahill AG, Tuuli MG, Macones GA, Odibo AO. Risk of stillbirth after 37 weeks in pregnancies complicated by small-forgestational-age fetuses. Am J Obstet Gynecol 2013;208(5):376. e1-376.e7

7 Pilliod RA, Cheng YW, Snowden JM, Doss AE, Caughey AB. The risk of intrauterine fetal death in the small-for-gestational-age fetus. Am J Obstet Gynecol 2012;207(4):318.e1-318.e6

8 Chen HY, Chauhan SP, Ward TC, Mori N, Gass ET, Cisler RA. Aberrant fetal growth and early, late, and postneonatal mortality: an analysis of Milwaukee births, 1996-2007. Am J Obstet Gynecol 2011;204(3):261.e1-261.e10

9 Berkley E, Chauhan SP, Abuhamad A; Society for Maternal-Fetal Medicine Publications Committee. Doppler assessment of the fetus with intrauterine growth restriction. Am J Obstet Gynecol 2012;206(4):300-308

10 RCOG Green-top Guideline No. 31. The Investigation and Management of the Small-for-Gestational-Age Fetus. Royal College of Obstetricians and Gynaecologists, London. February 2013. Available at: https://www.gestation.net/RCOG_Green_Top_-_SGA_2013.pdf

11 Lausman A, Kingdom J, Gagnon R, et al; Maternal Fetal Medicine Committee. Intrauterine growth restriction: screening, diagnosis, and management. J Obstet Gynaecol Can 2013;35(8):741-757

12 American College of Obstetricians and Gynecologist. Antepartum Fetal Surveillance. ACOG Practice Bulletin No. 145. Washington, DC: American College of Obstetricians and Gynecologist; 2014

13 Royal College of Physicians of Ireland. Fetal Growth RestrictionRecognition, Diagnosis and Management. RCPI Clinical Practice Guideline No. 28. Dublin, Ireland: Royal College of Physicians of Ireland; 2014

14 Jahn A, Razum O, Berle P. Routine screening for intrauterine growth retardation in Germany: low sensitivity and questionable benefit for diagnosed cases. Acta Obstet Gynecol Scand 1998; 77(6):643-648

15 Lindqvist PG, Molin J. Does antenatal identification of small-forgestational age fetuses significantly improve their outcome? Ultrasound Obstet Gynecol 2005;25(3):258-264

16 McCowan LM, Roberts CT, Dekker GA, et al; SCOPE consortium. Risk factors for small-for-gestational-age infants by customised birthweight centiles: data from an international prospective cohort study. BJOG 2010;117(13):1599-1607

17 Mattioli KP, Sanderson M, Chauhan SP. Inadequate identification of small-for-gestational-age fetuses at an urban teaching hospital. Int J Gynaecol Obstet 2010;109(2):140-143

18 Verlijsdonk JW, Winkens B, Boers K, Scherjon S, Roumen F. Suspected versus non-suspected small-for-gestational age fetuses at term: perinatal outcomes. J Matern Fetal Neonatal Med 2012; 25(7):938-943

19 Chauhan SP, Beydoun H, Chang E, et al. Prenatal detection of fetal growth restriction in newborns classified as small for gestational age: correlates and risk of neonatal morbidity. Am J Perinatol 2014; 31(3):187-194

20 Monier I, Blondel B, Ego A, Kaminiski M, Goffinet F, Zeitlin J. Poor effectiveness of antenatal detection of fetal growth restriction and consequences for obstetric management and neonatal outcomes: a French national study. BJOG 2015;122(4):518-527

21 McKenna D, Tharmaratnam S, Mahsud S, Bailie C, Harper A, Dornan J. A randomized trial using ultrasound to identify the 
high-risk fetus in a low-risk population. Obstet Gynecol 2003; 101(4):626-632

22 Chauhan SP, Rouse DJ, Ananth CV, et al. Screening for intrauterine growth restriction in uncomplicated pregnancies: time for action. Am J Perinatol 2013;30(1):33-39

23 American College of Obstetricians and Gynecologist, American Institute of Ultrasound in Medicine and Society of Maternal-Fetal Medicine. Method of Estimating Due Date. ACOG Committee Opinion No. 611. Washington, DC: American College of Obstetricians and Gynecologist; 2014

24 Chauhan SP, Hendrix NW, Magann EF, Morrison JC, Scardo JA, Berghella V. A review of sonographic estimate of fetal weight: vagaries of accuracy. J Matern Fetal Neonatal Med 2005;18(4):211-220

25 American College of Obstetricians and Gynecologist. Ultrasonography in Pregnancy. ACOG Practice Bulletin No. 101. Washington, DC: American College of Obstetricians and Gynecologist; 2009

26 Hadlock FP, Harrist RB, Sharman RS, Deter RL, Park SK. Estimation of fetal weight with the use of head, body, and femur measurements-a prospective study. Am J Obstet Gynecol 1985;151(3):333-337

27 Sandlin AT, Chauhan SP, Magann EF. Clinical relevance of sonographically estimated amniotic fluid volume: polyhydramnios. J Ultrasound Med 2013;32(5):851-863
28 Chauhan SP, Parker D, Shields D, Sanderson M, Cole JH, Scardo JA. Sonographic estimate of birth weight among high-risk patients: feasibility and factors influencing accuracy. Am J Obstet Gynecol 2006;195(2):601-606

29 Dahlke JD, Mendez-Figueroa H, Maggio L, Albright CM, Chauhan SP, Wenstrom KD. Early term versus term delivery in the management of fetal growth restriction: a comparison of two protocols. Am J Perinatol 2015;32(6):523-530

30 Boers KE, Vijgen SM, Bijlenga D, et al; DIGITAT study group. Induction versus expectant monitoring for intrauterine growth restriction at term: randomised equivalence trial (DIGITAT). BMJ 2010;341:c7087

31 Stergiotou I, Crispi F, Valenzuela-Alcaraz B, Cruz-Lemini M, Bijnens B, Gratacos E. Aortic and carotid intima-media thickness in term smallfor-gestational-age newborns and relationship with prenatal signs of severity. Ultrasound Obstet Gynecol 2014;43(6):625-631

32 Metz TD, Lynch AM, Wolfe P, Barry JS, Galan HL. Effect of small for gestational age on hemodynamic parameters in the neonatal period. J Matern Fetal Neonatal Med 2012;25(10):2093-2097

33 Alexander G, Himes J, Kaufman R, Mor J, Kogan M. United States national reference for fetal growth. Obstet Gynecol 1996; $87: 163-168$ 